\title{
A importância da valorização da avaliação docente pelo discente no ensino superior
}

\section{The importance of valuing teacher evaluation by students in higher education}

\author{
Glades Tereza Felix \\ Alessandra Alfaro Bastos**
}

\section{Resumo}

Este artigo situa-se no âmbito científico da avaliação da educação superior e trata da importância da valorização da avaliação docente pelo discente no ensino superior. Descreve um recorte de uma investigação maior realizada entre 2014-2017 com atores de um centro de formação de professores de uma universidade pública. Com base metodológica em Leite (2005) e Barber (1988), sob o escopo da metodologia da avaliação participativa (AP), a investigação de caráter quantitativo e qualitativo se desenvolveu por meio da aplicação de questionários semestrais, com 17 questões fechadas e uma aberta. Utilizaram-se os softwares Microsoft Office Excel, versão 2016, para as médias ponderadas das dimensões pedagógicas da unidade de ensino, e NVIVO 11, a partir da técnica de análise de conteúdo para as qualitativas. A combinação e o cruzamento de métodos e técnicas de pesquisa desvelaram que os docentes manifestam uma posição mais favorável em relação à avaliação quando os resultados desta são tratados de modo formativo, ajudando-os a melhorar seu desempenho.

Palavras-chave: Avaliação docente. Avaliação participativa. Discentes. Ensino superior. Qualidade.

\section{Abstract}

This article is located in the scientific scope of the evaluation of higher education and, in particular, deals with the importance of valuing teacher evaluation by students in higher education. It describes a cut of a larger investigation conducted between 2014-2017 with actors from a teacher training center of a public university. Methodologically based on Leite, (2005) and Barber, (1988), under the scope of the Participatory Evaluation (PA) methodology, quantitative research was developed through the application of a semester questionnaire with 17 closed questions and one open questionnaire. The software Microsoft Office Excel 2016 was used for the weighted averages of the pedagogical dimensions of the teaching unit and the NVIVO 11 software, from the technique of content analysis to the qualitative ones. The combination and cross-fertilization of research methods and techniques has revealed that teachers have a more favorable attitude towards evaluation when their results are treated in a formative way, helping them to improve their performance.

Keywords: Teacher evaluation. Participatory evaluation. Students. Higher education. Quality.

Recebido em 16/06/2018 - Aprovado em 30/08/2018

http://dx.doi.org/10.5335/rep.v26i1.8554

Licenciada em Pedagogia e mestre em Educação pela Universidade Federal de Santa Maria (UFSM). Doutora em Educação pela Universidade Federal do Rio Grande do Sul (Ufrgs), com pós-doutoramento em Acreditação e Avaliação na Ufrgs. Professora Associada no Centro de Educação da UFSM. E-mail: gladesfelix@hotmail.com

** Bacharel em Ciências Sociais e Jurídicas e mestre em Ciências Sociais pela UFSM. Doutoranda em Educação pela Ufrgs. Técnica em Assuntos Educacionais no Centro de Educação da UFSM. E-mail: alebastos@ymail.com 


\section{Introdução}

Este artigo foi elaborado na sequência da finalização de um programa de pesquisa que abrangeu dez projetos desenvolvidos no ciclo 2014-2017, cujo conteúdo procurou conhecer o nível de qualidade de indicadores educacionais ${ }^{1}$ intrínsecos às rotinas desenvolvidas nas instituições educacionais, dentre os quais, o desempenho dos docentes segundo a representação dos discentes.

Num plano de reatividade ao que está posto no Sistema Nacional de Avaliação da Educação Superior (Sinaes), antecipação e complementação à supervisão e à regulação estatal, em 2013, a unidade de ensino ouviu a comunidade e construiu um projeto de avaliação participativa, autônoma, continuada, global e integradora, para um ciclo avaliativo de quatro anos, tomando por referência o atual projeto pedagógico do centro formador (UFSM, 2012).

A ideia procurou estabelecer o contraponto aos fundamentos clássicos de formatos avaliativos prontos, fixos, ou formatos que, de fato, pouco têm dito sobre um bem público pertencente aos cidadãos de um espaço-tempo; como o ciclo de vida profissional dos docentes e sua relação com a reflexão, a aprendizagem e a mudança em favor de um processo automático, burocrático e de mérito para a progressão de carreira.

Com o avanço do neoliberalismo, é sabido que, cada vez mais, a avaliação tem sido peça-chave para a maioria dos Estados no estabelecimento da competitividade, do produtivismo acadêmico e da meritocracia, na ascensão e na estabilidade da carreira, com todos os docentes sendo submetidos, ano a ano, a avaliações sob o mesmo esquema técnico, mecânico e sem sentido para o seu aperfeiçoamento pessoal e profissional.

De modo geral, as concepções que mais circulam nos ambientes educativos são a avaliação burocrática e a avaliação formativa. Uma reluz sob o amparo do capital, alimentada pela classificação e maximização do produto, a outra se constitui numa alternativa de condição processual, crítica, sem premiação e/ou punição, sendo capaz de provocar a reflexão e o olhar sobre si mesmo.

A tensão entre o Estado e a universidade sobre a intencionalidade, a utilidade e o uso dos resultados avaliativos regulatórios nas instituições, nos cursos e na carreira do pessoal docente tem se reduzido à verificação de conformidade pouco eficiente na resolução dos problemas enfrentados por aqueles que vivem o cotidiano da academia.

Por esse viés, este artigo apresenta os resultados de uma pesquisa desenvolvida com os estudantes de cursos de licenciatura de uma unidade de ensino de uma instituição pública, visando conhecer suas representações e o efeito dos resultados do processo na prática docente. 
Sob o escopo da dimensão formativa na perspectiva da metodologia da avaliação participativa (AP), a pesquisa envolveu um grande volume de informações e compreendeu dados recolhidos por meio de questionários aplicados durante a série investigada.

O artigo, primeiro, versa sobre a relação entre ensino e avaliação docente e, depois, sobre a trajetória metodológica. $\mathrm{Na}$ sequência, analisa e discute os resultados da pesquisa com ênfase nos resultados qualitativos. Conclui-se que os docentes manifestam uma posição mais favorável em relação à avaliação quando os resultados desta são tratados de modo formativo, ajudando-os a melhorar seu desempenho.

\section{A relação entre ensino e avaliação docente}

Cada vez mais, na sociedade contemporânea, a avaliação, de modo geral, efetiva-se como uma prática social imprescindível ao diagnóstico, à interpretação, à melhoria e ao aperfeiçoamento de complexos produtos, serviços e insumos, entre eles, a questão da qualidade da educação e do processo ensino-aprendizagem.

Nas últimas três décadas, é visível a preocupação da sociedade com a eficácia dos sistemas educativos, principalmente, a partir da expansão da educação presencial e a distância, da demanda de novos e diversificados cursos, do incremento e da reformulação dos currículos, da formação continuada dos profissionais da educação, da inovação da gestão e da organização das instituições.

Em tese, espera-se que a avaliação, em geral, contribua para a melhoria da vida das pessoas e dos profissionais, tendo como horizonte a aceitação e o entendimento de que há uma multiplicidade de abordagens de avaliação, que, por conseguinte, são utilizadas para os mais diferentes objetivos.

Em se tratando de avaliação docente, o renomado Joint Committee on Standards for Evaluation defende e reconhece a sua importância como elemento primordial aos sistemas educativos e à valorização da própria profissão, concebendo-a como um "processo sistemático do desempenho dos profissionais e ou de suas qualificações, ligada com a função profissional e a missão da área educacional” (1981, p. 23).

Por essa amplitude, antes de tudo, para fundamentar e qualificar o debate sobre avaliação docente, é essencial a compreensão do que significa ensinar e do que faz ou deve fazer, de fato, um professor na acepção da função; isso pode determinar a concepção de uma abordagem de avaliação, seja por parte do Estado, das instituições educativas ou até do próprio docente.

Logicamente, esse tipo de implicação pode enfrentar dissensos devido ao fato de essa questão ser atravessada de princípios morais, políticos, religiosos, edu- 
cacionais, culturais, etc. Contudo, é possível identificar, nas pesquisas de Gage (1978), Wise et al. (1984), Goodlad (2004) e Eisner (2005), a efervescência do debate a respeito da tarefa de ensinar.

Tomando por base concepções de ensino e concepções de avaliação docente, baseando-se nas investigações clássicas de Cristelo (2006), Day (1992) e Darling-Hammond, Wise e Pease (1986), Fernandes é categórico em afirmar que:

Todo o sistema de avaliação tem de ter em consideração uma concepção da tarefa de ensinar e um qualquer processo que permita avaliar a competência, o desempenho e a eficácia dos professores. Assim, o ensino, ou o trabalho de ensinar, pode ser considerado sob quatro perspectivas distintas: o Ensino como Trabalho; o Ensino como Ofício; o Ensino como Profissão e o Ensino como Arte (2009, p. 16).

Em consideração à classificação supracitada, é faz necessário, a título de conhecimento, o apontamento de atributos relativos a cada uma dessas perspectivas, objetivando-se, assim, o discernimento, a identificação da teoria e da prática, bem como da relação desses modelos com a realidade. Com base em Fernandes (2009), sintetizamos alguns elementos essenciais.

O ensino como trabalho se estabelece perante a ótica racionalista e burocrática do dever de ensinar. Basta o professor assumir a sua função para que alcance os resultados. Esta é uma visão acrítica e reducionista do papel do professor. A avaliação centra-se na fiscalização do trabalho do professor, na análise de resultado dos alunos e no cumprimento dos planos de aula.

No ensino como ofício, Fernandes (2009, p. 17) resume que ensinar é utilizar e aplicar, adequadamente, as regras e as técnicas prescritas pelas autoridades. Desse modo, o papel da avaliação dos professores é centrado na verificação do cumprimento de ditames.

O ensino como profissão considera um professor com sólidos conhecimentos teóricos. Segundo Fernandes (2009, p. 17), professores são profissionais que se desenvolvem, autonomamente, em cooperação e colaboração com seus pares, ensinam de acordo com elevados padrões de conhecimento científico e pedagógico, em que predomina a autoavaliação e a avaliação por pares.

O ensino como arte, para Fernandes (2009, p. 17), é uma concepção em que as práticas são orientadas para cada pessoa; portanto, em total desacordo com a estandardização de ações na docência; há predominância de dinâmicas de sala de aula baseadas na intuição, na dramatização, na improvisação e na criatividade. "Tal como nos é dito por Gage (1978), a avaliação dos professores nesta perspectiva alinha-se em características e ou qualidades globais e holísticas" (FERNANDES, 2009 , p. 17). A proposta é de valorização da pessoa que o professor é, o que ele pensa e sente sobre sua profissão. 
Outra abordagem interessante de ensino que pode contribuir para o debate envolve os denominados "Modelos de Produto e de Processo", segundo os estudos iniciais de Wise et al. (1984), cujo escopo tem servido de base para a avaliação docente em muitos sistemas educativos; tais modelos receberam a contribuição de Day (1992) e Cristelo (2006).

Num processo de avaliação docente, segundo o modelo de produto, a estratégia principal é recolher e analisar dados relativos à competência do desempenho e à eficácia do docente.

É a utilização de procedimentos que permitem medir tão somente quanto possível o desempenho dos professores para que sejam operacionalizadas as ações necessárias para ultrapassar os problemas que eventualmente forem detectados [...] tendem a ter uma natureza prescritiva, muito associada as finalidades previstas no currículo proposto, e num certo sentido mais próximos de visões e preocupações das autoridades educativas, em garantir que sejam mínimas as diferenças entre o currículo proposto, o ensinado pelos professores e o aprendido pelo aluno (FERNANDES, 2009, p. 20).

É por estas características que, para Fernandes (2009), o referido modelo parece ter muita similaridade com elementos que sustentam as concepções do ensino como trabalho e do ensino como ofício.

Em relação à avaliação de professores no modelo de processo, o cerne da questão é melhorar a qualidade do ensino. De acordo com Fernandes, "[...] o desenvolvimento profissional dos professores tem de estar relacionado com a produção de ideias e de reflexões que surgem ao longo do processo" (2009, p. 20).

As informações avaliativas que se vão obtendo ao longo do processo são situadas e específicas de um determinado contexto e deverão servir como estímulo e incentivo ao desenvolvimento profissional dos docentes. Assim, o modelo de processo está mais próximo das práticas do dia-a-dia dos professores, das necessidades reais e da sua cultura profissional... Estando mais próximas das concepções do Ensino como Profissão e do Ensino com Arte (FERNANDES, 2009, p. 20).

Até o momento, optamos pela fundamentação de correntes e culturas diferentes de ensino e de avaliação docente, que, por vezes, convivem de modo complementar nos sistemas educativos. Entretanto, independente do modelo que os sistemas e ou as universidades decidam adotar, para acompanhar a qualidade do ensino e o desempenho dos docentes, é necessário, antes, assumir determinados princípios, valores, metodologias e procedimentos, com base em respostas claras para as seguintes questões: avaliar para quê? Avaliar o quê? Como avaliar?

As respostas para essas questões podem alavancar o ponto de partida para o autodesenvolvimento das instituições em contradita ao sufoco das regras da regulação estatal. Logicamente, isso implica a cultura da prática da liberdade e da autonomia institucional, cujo caminho é capaz de favorecer o avanço de modos de 
ensino e de avaliações construtivas, em consonância com o estatuto profissional da carreira docente. A seguir, é apresentada a linha metodológica do trabalho desenvolvido.

\section{Trajetória metodológica}

A pesquisa desenvolvida durante o ciclo tomou por base a linha metodológica dos estudos de Leite (2005) e Barber (1988), sustentados na avaliação participativa (AP).

Em função da valorização da participação, tal escolha se encaixou melhor na expectativa demonstrada pela comunidade com a avaliação, além de ser um modelo que faz um contraponto aos paradigmas clássicos de avaliar; sendo, pois, impulsionador do desafio e da inovação no ambiente universitário.

Sendo assim, trata-se de uma avaliação de caráter processual, distante dos modelos fixos e formatados, que abriga em seu escopo princípios que identificam pressupostos da democracia forte, o que Barber (1988) reconhece ser um elemento primordial, porque a distingue de outras classificações de avaliação, uma vez que avaliação participativa requer:

[...] sensibilização e pactuação ou negociação política; constitui um instrumento epistemológico para o pensamento e a ação política no espaço público; envolve a criação de uma comunidade do bem público; se exerce através da cogestão e do autogoverno de diferentes atores; institui autonomia dos sujeitos, dos coletivos e da instituição; nutre-se da autocrítica, autovigilância e autolegislação permanentes e exige seu tempo próprio (LEITE, 2005, p. 110).

Tanto Barber (1988) como Leite (2005) seguem o mesmo raciocínio ao afirmar que a prática desta concepção surgiu do anseio de "transformar e reformar a universidade, de modo permanente", sendo assim, a avaliação de cunho participativo é inerente à democracia forte, plena ou direta, na representação de um regime de governo capaz de resolver problemas e conflitos por meio de uma política de participação, com negociação, autocrítica, autovigilância e autolegislação.

Desse modo, a iniciativa da prática da avaliação docente pelo discente na instituição começou em $2014^{2}$ na unidade de ensino por meio deste projeto, tendo sido implementados seis processos avaliativos no âmbito dos docentes e dos discentes de cinco cursos de graduação.

As referidas avaliações se desenvolveram por meio de quatro fases distintas e complementares: a sensibilização, a implementação, os resultados e a meta-avaliação. A sensibilização foi a fase mais importante e com maiores tempo e recursos investidos; desenvolveu-se antes de cada evento, por meio de seminários, enquetes, 
validação do instrumento, testagem do ambiente virtual, folders, visitas às salas de aula, cartazes, mensagens eletrônicas, reuniões com os segmentos discente e docente, para devolutivas e revisões da metodologia.

A implementação se deu por meio da aplicação de um questionário on-line, contendo 17 questões fechadas, das quais 13 estavam subdivididas em 6 dimensões (plano da disciplina, conteúdo da disciplina, aproveitamento das aulas, metodologia, avaliação e relação docente-estudante); as demais se referiam à docência orientada e à autoavaliação do estudante; por fim, tinha-se uma questão aberta de livre manifestação; o acesso foi por tempo determinado, no portal do aluno, com login e senha específicos.

Para a fase dos resultados, foram produzidos dois tipos de dados: quantitativamente, por meio do cálculo dos pontos da escala likert de cinco posições, com o uso de ferramenta apropriada, foram obtidas as médias ponderadas e o desvio padrão, por ano, semestre, curso, departamento e unidade; e, qualitativamente, por meio da frequência de respostas dos discentes na questão aberta, foram identificados os pontos positivos e os negativos.

A meta-avaliação ocorreu em todos os momentos das referidas avaliações, uma vez que a avaliação participativa, devido à sua natureza, permitiu um movimento dialético durante toda a pesquisa, favorecendo, assim, a melhoria das deficiências e o aperfeiçoamento de partes do processo, visando aprimorar os passos seguintes.

\section{Resultados}

Foi disponibilizado, durante o ciclo avaliativo, um questionário para cada disciplina em que o estudante estava matriculado, perfazendo um total de 6.983 matrículas, das quais 2.132 responderam ao menos um questionário, sinalizando uma participação média de $30 \%$ no ciclo cujo resultado revela que a avaliação docente ainda não é um acontecimento valorizado culturalmente pelos discentes.

O tratamento dos dados da pesquisa quantitativa apontou, por meio do software Microsoft Office Excel, versão 2016, os resultados das médias por dimensão pedagógica, na forma gráfica, para a unidade de ensino no ciclo investigado, conforme o Gráfico 1. 
Gráfico 1 - Médias, dimensões pedagógicas, unidade de ensino (2014-2017)

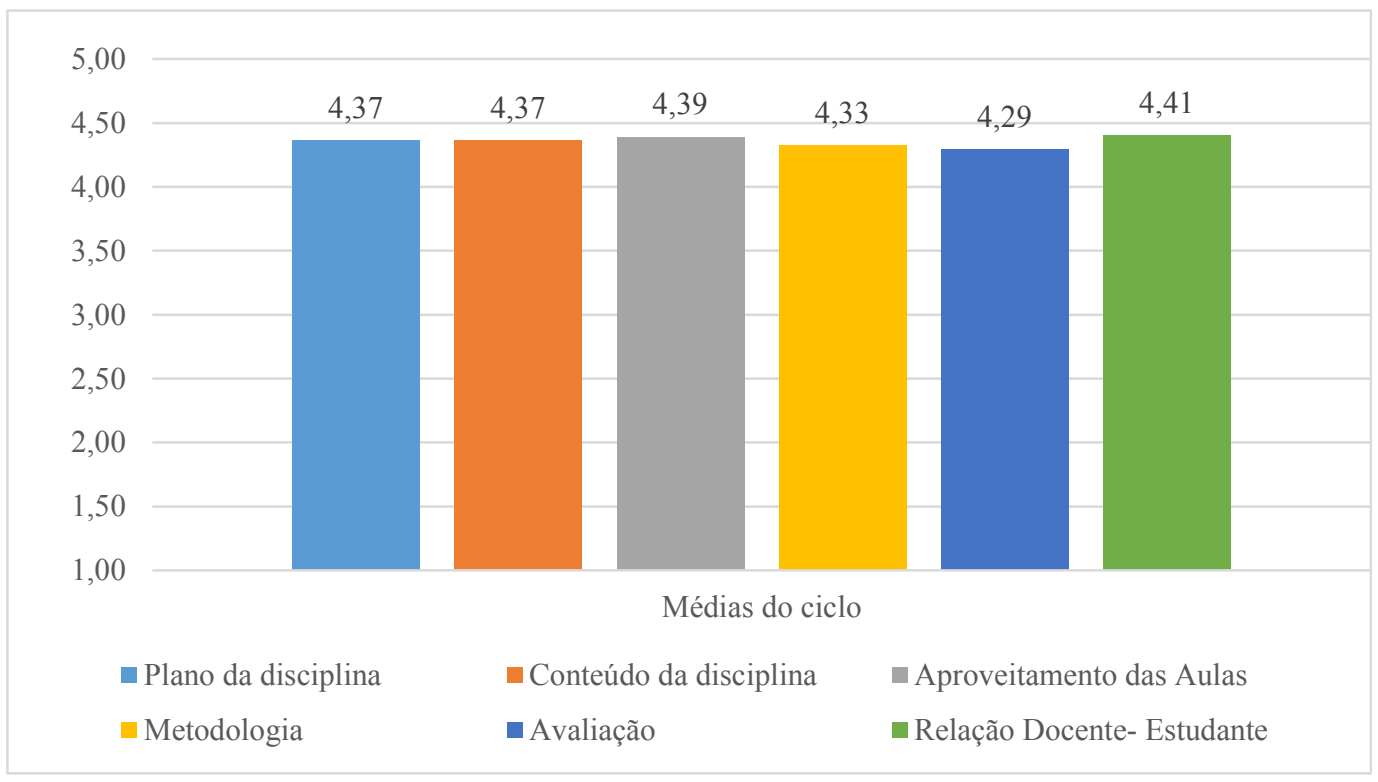

Fonte: UFSM (2018).

Por meio dos resultados da pesquisa quantitativa, verifica-se que as médias se mantiveram elevadas em todo o ciclo, acima de 4,00, o que denota o excelente desempenho dos docentes com base nas questões objetivas.

A dimensão com melhor média no ciclo foi a relação docente-estudante, com 4,41, já a dimensão avaliação obteve a menor média, 4,29; a diferença é pequena, porém, evidencia-se como um ponto a ser melhorado, pois se manteve durante todo o ciclo com a menor média.

Contudo, percebe-se que, mesmo as médias tendo se mantido altas em todas as dimensões, esse fato não repercutiu de modo positivo na visão dos docentes, pois, conforme o processo avançava, estes passaram a dispensar menor importância aos resultados quantitativos, isso ficou evidente na baixa adesão aos debates.

Tal apatia talvez se traduza na frustração dos docentes, que, possivelmente, esperavam uma contribuição mais realista da parte dos discentes; de outro modo, é provável que o medo, a reprovação e a perseguição os tenham levado a declinar de opiniões mais sinceras, o que é, perfeitamente, explicado pela falta de cultura avaliativa na instituição.

Diante de tal desconfiança, um fato importante de ser resgatado é que, em todos os debates, enfatizou-se que o processo pautar-se-ia no princípio da "não pre- 
miação e não punição" para todos os envolvidos, conforme previa o antigo Programa de Avaliação Institucional das Universidades Brasileiras (Paiub) (BRASIL, 1994).

Portanto, com base neste acordo, somado à impossibilidade de qualquer meio de identificação discente, perdeu-se a oportunidade de os dados quantitativos também servirem de fonte válida e valiosa aos docentes; caracterizando-se, pois, como um ponto a ser reforçado nas futuras edições.

Para análise da questão aberta, foi utilizado o software NVivo 11, que procedeu à frequência das respostas. Foram encontradas 2.988 mensagens, as quais foram catalogadas e categorizadas por dimensão e questão, sendo classificadas em positivas ou negativas, de acordo com o método de análise de conteúdo de Minayo (2014). A seguir, os resultados da frequência (positivo ou negativo) das dimensões pedagógicas são apresentados no Gráfico 2.

Gráfico 2 - Frequência de respostas, unidade de ensino (2014-2017)

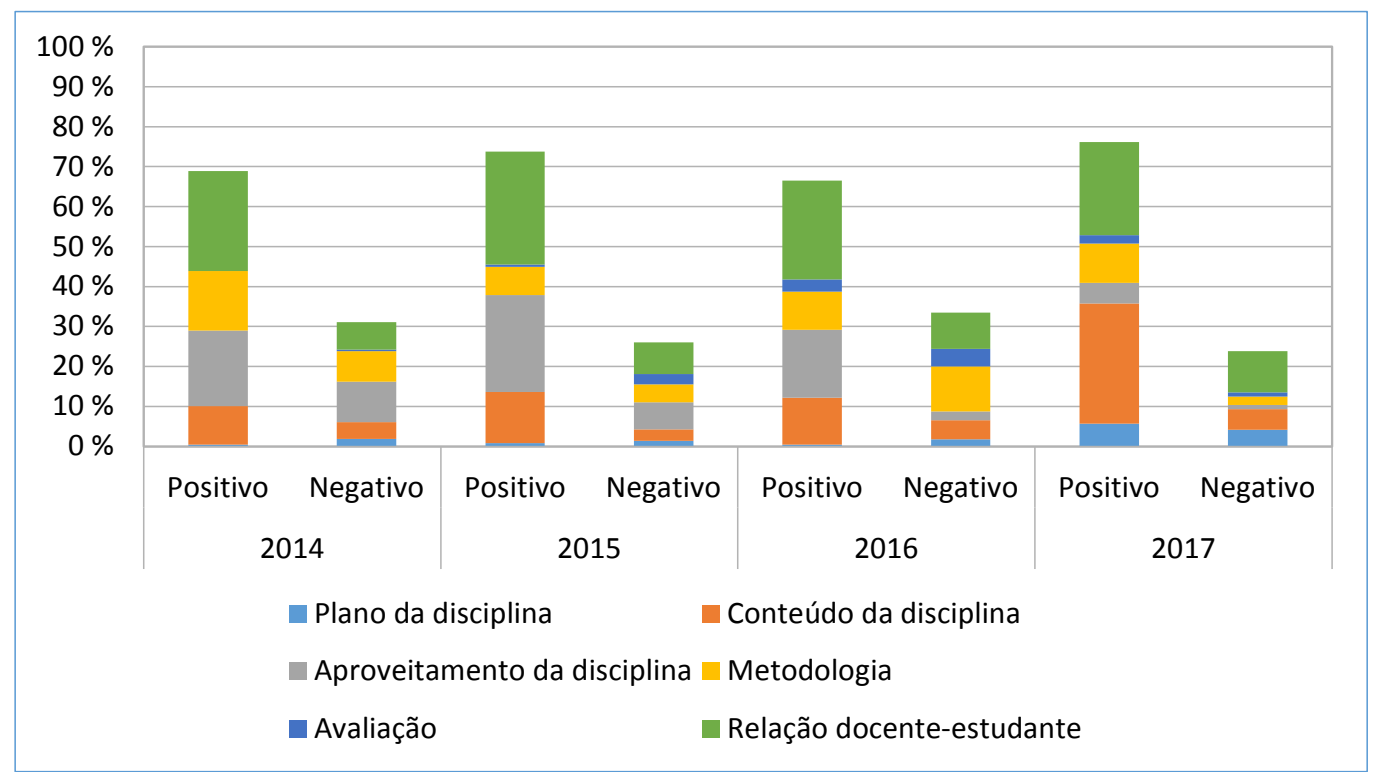

Fonte: UFSM (2018).

Pode-se verificar que a categoria positiva prepondera, todavia, comparativamente à pesquisa quantitativa, observa-se que os pontos a serem melhorados são indicados, majoritariamente, na dimensão metodologia, como descrito nos excertos a seguir: 
Acredito que a professora muitas vezes assume uma postura autoritária, isso de certa forma transforma o convívio causando um desinteresse pela disciplina (Estudante 2014).

Mas acho que ele podia se preocupar mais com o interesse do aluno e buscar novas formas de fazer com que queiramos estar em sala de aula (Estudante 2015).

Achei uma disciplina bastante exaustiva, com muitas leituras e quase nenhum debate. Acredito que, se o professor passasse a ideia do conteúdo proposto e organizasse debates em sala que abordassem o tema, seria bem mais fácil a compreensão da disciplina (Estudante 2016).

Um exemplo de professora!!! Muito boa, traz ideias inovadoras, diversifica, traz discussões para a turma, torna as aulas deliciosas de se frequentar! Maravilhosa mesmo, só elogios (Estudante 2014).

Gosto das aulas, acho bem diversificado, com bastante interação da turma, não tenho o que reclamar (Estudante 2015).

Os debates em sala de aula ajudaram na fixação do conteúdo. O número de trabalhos cobrados no semestre foi suficiente, uma vez que em outras disciplinas eram cobrados trabalhos semanais (Estudante 2016).

É evidente que tais manifestações contradizem os achados de que há um "super professor" no centro de ensino, pois as diferenças de opiniões no desvelamento de críticas, sugestões, comentários positivos e muitos pontos negativos na prática docente são indícios de que a investigação qualitativa contribuiu, muito mais, para o objetivo da pesquisa, que se pautou na representação dos discentes sobre o desempenho docente e os efeitos desta na valorização da prática docente.

Assim, a triangulação de métodos, referenciais e recursos humanos possibilitou a análise de múltiplos pontos de vista dos participantes, oferecendo um mapeamento mais completo da percepção dos alunos e uma melhor compreensão dos resultados, gerando subsídios consistentes para implementação de mudanças. Nesse sentido, a avaliação participativa se sobrepõe às avaliações em larga escala, pois seus resultados servem para a reflexão de discentes e docentes em oposição ao ranqueamento de instituições proporcionado por estas.

\section{Conclusão}

Tomando por base as principais contribuições advindas do estudo realizado no ciclo 2014-2017, que tratou de conhecer a representação dos discentes de cinco cursos de licenciatura sobre a qualidade do desempenho docente e os efeitos desta na valorização da prática docente, podem ser elencadas as seguintes conclusivas. 
O uso da metodologia da avaliação participativa demonstrou-se eficiente e adequado, porque permitiu a sistematização de um claro diagnóstico sobre a prática docente na unidade de ensino.

Um aspecto importante detectado foi o fato de a avaliação docente pautar-se pelo princípio da "não premiação e ou não punição", o que desmistifica a reação dos discentes supervalorizarem a avaliação quantitativa. Outro aspecto se refere ao pouco interesse dos discentes em participar da avaliação, pois, apesar de todo o investimento na sensibilização durante o ciclo, esperava-se que o índice de participação fosse acima de 30\%; isso talvez se explique pela ausência de uma cultura de avaliação por parte da própria instituição.

Contudo, a implementação deste estudo, a partir de correntes e culturas diferentes de ensino e de avaliação, demonstrou ser, perfeitamente, viável e valiosa a construção de projetos avaliativos antecipativos, reativos e autônomos em complementação ao Sinaes.

Foi por meio deste desafio que se conseguiu "separar o joio do trigo", ou seja, nem sempre a ideia dominante de que conhecemos o cotidiano pela medida do que vimos e ouvimos corresponde à realidade; até o domínio científico do que é "ensinar" mostrou-se, ainda, distante de nos levar a um conjunto estável de características que se adeque a todas as realidades.

$\mathrm{O}$ reconhecimento disso remete às instituições a possibilidade de melhoria da qualidade, de modo geral, por meio da construção de sistemas de avaliação internos, capazes de servir, também, ao desenvolvimento pessoal e profissional dos docentes, para além da burocracia e do mérito da progressão.

No caso em estudo, foi por meio dos resultados da avaliação qualitativa, expressada na autenticidade, na criticidade e na sinceridade discente, que se reconheceu a existência de um processo avaliativo de cunho formativo, que acabou por movimentar, também, os docentes, uma vez que melhor descreveu o contexto.

Portanto, quando os resultados são reconhecidos e tratados de modo formativo ou de acordo com o modelo de processo de Wise et al. (1984), observou-se que a tendência dos docentes é a manifestação favorável à avaliação, porque, de fato, os resultados poderão contribuir para a melhoria de seu desempenho.

Por fim, com base nas conclusões da pesquisa, alerta-se para a importância de as instituições valorizarem processos de avaliação docente pelo discente, para além do que está posto pelo sistema; em tempos de expansão, competitividade, inovação, formação continuada e novas demandas para a educação superior, isso poderá ser um diferencial para o alcance da qualidade. 


\section{Notas}

1 Docente pelo discente, estudantes-estagiários; docentes-orientadores; instituições conveniadas; gestores; técnico-administrativos; serviços privados (portaria, reprografia, lancheria, segurança, limpeza); egressos, pesquisa e extensão.

2 Entre 2014 e 2015, ocorreram avaliações anuais; entre 2016 e 2017, avaliações semestrais. A partir de 2016, por questões de regulação, a instituição passou a aplicar idêntico processo, quando se julgou procedente aderir a tal implementação, utilizando-se dos resultados para a continuidade do projeto global da unidade de ensino.

\section{Referências}

BARBER, Benjamin. Democracia forte. Paris: Desclée Brower, 1988.

BRASIL. Ministério da Educação. Programa de Avaliação Institucional das Universidades Brasileiras - Paiub. Brasília, DF: MEC, 1994.

CRISTELO, S. Avaliação de professores: estudo de caso no $1^{\circ}$ ciclo do ensino básico. Dissertação (Mestrado em Ciências da Educação) - Faculdade de Psicologia, Universidade de Lisboa, Lisboa, 2006.

DARLING-HAMMOND, L.; WISE, A.; PEASE, S. Teacher evaluation in the organization context: a review of the literature. In: HOUSE, E. (Ed.). New directions in educational evaluation. London: Falmer, 1986. p. 285-328.

DAY, C. Avaliação do desenvolvimento profissional dos professores. In: ESTRELA, E.; NÓVOA, A. (Org.). Avaliações em educação. Novas perspectivas. Lisboa: Educa, 1992. p. 89-104.

EISNER, E. Reimagining schools: the selected works of Elliot W. Eisner. New York: Routledge, 2005.

FERNANDES, D. Avaliação do desempenho docente: desafios, problemas e oportunidades. Lisboa: Texto Editores, 2009.

GAGE, N. The scientific basis of the art of teaching. New York: Teachers College Press, 1978.

GOODLAD, J. A place called school. New York: MacGraw-Hill, 2004.

JOINT COMMITTEE ON STANDARDS FOR EVALUATION. The personnel evaluation standards. Newbury Park: Sage, 1981.

LEITE, Denise. Reformas universitárias. Avaliação institucional participativa. Petrópolis, RJ: Vozes, 2005.

MINAYO, Maria Cecília de Souza. O desafio do conhecimento: pesquisa qualitativa em saúde. 14 . ed. São Paulo: Hucitec, 2014.

WISE, A. et al. Teacher evaluation: a study of effective pratice. June: Rand Corporation, 1984.

UNIVERSIDADE FEDERAL DE SANTA MARIA. Centro de Educação. Projeto político-pedagógico. Santa Maria: UFSM, 2012.

Centro de Educação. Comissão Institucional de Avaliação do Centro de Educação (CAICE). Cadernos Avaliação em Revista: avaliação docente pelo discente. Séries 2014/2, 2015/1, 2016/1 e 2016/2, n. 4. Santa Maria: Imprensa Universitária, 2018. 